\title{
Absence of pain in subjects with advanced radiographic knee osteoarthritis
}

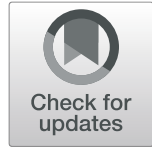

Kyeong Min Son ${ }^{1+}$, Jeong Im Hong ${ }^{2 \dagger}$, Dong-Hyun Kim³ ${ }^{3}$ Dae-Gyu Jang ${ }^{4}$, Michel D. Crema ${ }^{5}$ and Hyun Ah Kim ${ }^{2^{*}}$ (D)

\begin{abstract}
Background: To investigate the frequency of pain among subjects with advanced radiographic knee osteoarthritis $(\mathrm{OA})$ defined as Kellgren-Lawrence $(\mathrm{KL})$ grade 4 and clinical features associated with pain.

Methods: Subjects from the Hallym Aging Study (HAS), the Korean National Health and Nutrition Examination Survey (KNHANES), and the Osteoarthritis Initiative (OAI) were included. Participants were asked knee-specific questions regarding the presence of knee pain. Clinical characteristics associated with the presence of pain were evaluated with multivariable logistic regression analysis.
\end{abstract}

Results: The study population consisted of 504, 10,152 and 4796 subjects from HAS, KNHANES, and OAl, respectively. $\mathrm{KL}$ grade $4 \mathrm{OA}$ was identified in $9.3,7.6$, and $11.5 \%$ of subjects, while pain was absent in $23.5,31.2$, and $5.9 \%$ of subjects in $\mathrm{KL}$ grade 4 knee $\mathrm{OA}$, respectively. After multivariable analysis, female gender showed a significant association with pain in the KNHANES group, while in the OAl group, younger age did. Advanced knee OA patients without pain did not differ from non-OA subjects in most items of SF-12 in both Korean and OAl subjects. Total WOMAC score was not significantly different between non-OA and advanced knee OA subjects without pain in the OAl.

Conclusions: Our study showed that a considerable number of subjects with KL grade $4 \mathrm{OA}$ did not report pain. In patients whose pain arises from causes other than structural damage of the joint, therapeutic decision based on knee X-ray would lead to suboptimal result. In addition, treatment options focusing solely on cartilage engineering, should be viewed with caution.

Keywords: Osteoarthritis, Pain, Knee

\section{Background}

Osteoarthritis (OA) is the most common form of arthritis affecting the elderly, and was ranked as the 11th leading cause of years lived with disability (YLD) globally, with higher rank (6th) especially among Asian countries [1]. In addition, YLD due to knee OA increased by $64 \%$ from 1990 to 2010, reflecting aging of the population [1]. Knee pain due to OA is a key symptom influencing the decision to seek medical attention, and previous reports have suggested that knee pain is a

\footnotetext{
* Correspondence: kimha@hallym.ac.kr

${ }^{\dagger}$ Kyeong Min Son and Jeong Im Hong contributed equally to this work.

${ }^{2}$ Division of Rheumatology, Department of Internal Medicine, Hallym University Sacred Heart Hospital, Anyang, Kyunggi, South Korea

Full list of author information is available at the end of the article
}

better predictor of disability than radiographic changes $[2,3]$. Radiographic OA changes are poorly correlated with pain and physical function, and the risk factors for radiographic knee OA may not be the same as those for knee pain [4-6]. Although radiography has long been used for evaluation of knee OA and knee pain, caution is required in its use to guide therapeutic decisions, such as whether to perform knee replacement surgery.

The mechanistic causes of pain in knee OA is not well understood, although multiple factors, including biological and psychological causes, may all play important roles. Hyaline cartilage, the main focus of interest in both clinical and laboratory research on $\mathrm{OA}$, is an aneural structure [7]. Thus, while clinicians tend to relate structural damage to the cartilage in people with

(c) The Author(s). 2020 Open Access This article is licensed under a Creative Commons Attribution 4.0 International License, which permits use, sharing, adaptation, distribution and reproduction in any medium or format, as long as you give appropriate credit to the original author(s) and the source, provide a link to the Creative Commons licence, and indicate if changes were made. The images or other third party material in this article are included in the article's Creative Commons licence, unless indicated otherwise in a credit line to the material. If material is not included in the article's Creative Commons licence and your intended use is not permitted by statutory regulation or exceeds the permitted use, you will need to obtain permission directly from the copyright holder. To view a copy of this licence, visit http://creativecommons.org/licenses/by/4.0/ The Creative Commons Public Domain Dedication waiver (http://creativecommons.org/publicdomain/zero/1.0/) applies to the data made available in this article, unless otherwise stated in a credit line to the data. 
knee pain, it is unable to provide sensory nociceptive input and is, therefore, an unlikely source of pain. Radiographic knee OA accompanied with pain occurs in approximately $37 \%$ of persons aged 60 years or older, whereas knee pain is reported at a rate of $15-81 \%$ among subjects with radiographic knee OA [6, 8-11]. The discordance between knee pain and knee radiographic findings was suggested to be more prominent in cases of mild grade OA. However, discordance was also reported in Kellgren-Lawrence (KL) grade 3 or 4, with $25.8 \%$ of subjects reporting no pain in the knee $[6,12$, 13]. KL grade 4 OA represents the most severe subgroup of radiographic OA, showing marked joint space narrowing (often bone-to-bone appearance reflecting almost total loss of cartilage), large osteophytes, severe subchondral sclerosis, and definite bony deformity. Patients presenting with knee pain and KL grade 4 radiographs are more likely to be offered joint replacement surgery, because a previous cohort study showed that a higher degree of radiographic OA was related to shorter time until surgery, and because it was consistently reported that patients with higher grade OA have a better prognosis after total hip replacement (THR) or total knee replacement (TKR) than patients with lower grade OA $[14,15]$. In patients whose pain arises from causes other than structural damage of the joint, however, decision of surgery solely based on knee X-ray would lead to suboptimal result.

This study was performed to elucidate the frequency of pain among subjects with advanced radiographic knee OA defined as KL grade 4 OA. Clinical characteristics associated with pain among advanced radiographic knee OA subjects were examined. In addition, knee function and quality of life among non-OA, advanced radiographic knee OA without pain and with pain were compared. Two databases obtained from Korean community residents and the Osteoarthritis Initiative (OAI) publicuse data sets were used and analyzed.

\section{Methods \\ Subjects}

Subjects were from two Korean registries, i.e., the Hallym Aging Study (HAS) and the fifth Korean National Health and Nutrition Examination Survey (KNHANES-V, 20102012), and the OAI. HAS is a prospective cohort study of health among elderly community residents of Chuncheon, a city about $120 \mathrm{~km}$ east of Seoul. The methods have been described elsewhere in detail [3]. Briefly, eligibility criteria included age $\geq 50$ years and residence within the borders of the survey area for at least 6 months before the survey. This study began in 2004, with follow-up examinations planned every 3 years until 2010, and the study population included subjects recruited in 2007. KNHANES was a cross-sectional and nationally representative survey conducted by the Division of Chronic Disease Surveillance of the Korean Center For Disease Control and Prevention [16]. This survey used a stratified, multistage, clustered sampling design based on the 2005 National Census data to randomly select a population based across 500 national districts to represent the civilian, non-institutionalized, South Korean population, and sample design and size were estimated such that the annual survey results were representative of the whole population in Korea [17]. In the present study, we selected all subjects $\geq 50$ years ( $n=$ $10,152)$ who had an OA examination that included radiographic examination of the knee and a survey about knee pain [18]. The OAI is a nationwide research study sponsored by the National Institutes of Health. The OAI study included men and women aged 45-79 years with, or at risk of, symptomatic tibiofemoral knee OA, to investigate the natural history of knee OA across the spectrum of disease and to study the relationships of imaging, and biochemical and genetic markers with the clinical course of OA. We used the baseline questionnaire for the cohort of 4796 participants from November 2008, which is publicly accessible at https://data-archive.nimh.nih.gov/oai.

Demographic information included in the three surveys were sex, age, body mass index (BMI), education level, marital status, smoking history, alcohol consumption, household income, and comorbidities. Comorbidity health information was obtained using a self-reported questionnaire survey (see Additional file 1) and included cerebrovascular accident (CVA), myocardial infarction, diabetes mellitus, hyperlipidemia (not available in the OAI groups), and osteoporosis.

\section{Definition of knee pain}

In the HAS study, knee pain was assessed by asking, "Have you had pain, aching, or stiffness lasting at least a month in your knee?" In the KNHANES study, knee pain was assessed by asking, "Have you had an episode of knee pain lasting more than 30 days within the last 3 months?" In OAI, knee pain was assessed by asking, "During the past 12 months, have you had pain, aching, or stiffness in or around your right (left) knee on most days for at least one month?" Subjects without knee pain were defined as those who responded "No" to the screening question in the cohort.

\section{WOMAC score}

WOMAC score is the most commonly used diseasespecific measure of outcome in OA. The WOMAC score was based on the objective of defining the dimensionality of pain and disability in osteoarthritis of the hip and/ or knee [19-21]. WOMAC score for knee pain was collected in HAS and OAI. In HAS, WOMAC score was based on a $0-100-\mathrm{mm}$ visual analog scale, and the total score ranged from 0 to 2400 . In the OAI study, 
WOMAC score was based on categorical score using the Likert scale and total score ranged from 0 to 96 .

\section{SF-12}

To assess general health status, the self-administered Medical Outcomes Study Short Form 12 (SF-12) was used, which is a reduced version of the SF-36 in that it has the same number of subscales, but with fewer items per subscale. Scores are derived from 8 domains and higher scores represent better health [22].

\section{Radiographic assessment}

In the HAS study, radiographic evaluations consisted of bilateral weight-bearing anteroposterior (AP), semiflexed knee radiographs, using a Plexiglas frame (SYNA RC, San Francisco, CA) to standardize knee positions, according to the manufacturer's recommendations. Radiographic grade of knee OA was assessed using the $\mathrm{KL}$ grading and were read twice by one reader (an academically based rheumatologist). The reproducibility of intrareader assessment was high (for OA vs. no OA, weighted Cohen's $\mathrm{k}=0.89$ ). In the KNHANES study, bilateral weight-bearing AP knee radiographs were taken using a SD3000 Synchro Stand (Accele Ray Shinyoung Co., Seoul, Korea). Radiographic changes related to OA were assessed using the KL grading system. The radiographic digital images were graded by two radiologists, with concordant grades accepted. When there was a difference of 1 grade between the two radiologists, the higher grade was accepted. If the discrepancy was $>1$ grade, a third radiologist was consulted, and the grade concordant with the third grader was accepted [23]. Inter-rater agreement within 1 grade of difference between the two radiologists was $92.8 \%$ and weighted Cohen's $\mathrm{K}$ coefficient was 0.65 .In OAI, bilateral posterior-anterior (PA) fixed flexion view was taken. Readers at each clinical center were trained using a classification based on the OARSI atlas grades, and had to achieve acceptable agreement with the central reading. In the present study, the definition of advanced radiographic knee OA was the presence of KL grade 4 in any tibiofemoral joint. The definition of non-OA was the KL grade 0 regardless the knee pain.

\section{Statistical analysis}

To compare three groups (HAS, KNHANES, and OAI), continuous variables were examined using ANOVA or Kruskal Wallis test and categorical variables using the chi-square test. To compare advanced radiographic knee OA subjects with pain to those without pain, continuous variables were tested using two-sample $t$ test or MannWhitney $U$ test and categorical variables were examined using the chi-square test. In multivariable analysis for risk factors of knee pain, we used ordinal regression analysis with the backward selection method with all clinical factors (sex, age, BMI, education level, marital status, smoking history, alcohol consumption, household income, and comorbidities). We used the backward selection method since it is one of the most widely used methods in clinical studies. We also used forward and stepwise selection methods, and selected variables in the model were the same for each dataset.

Crude odds ratio (OR) for risk factors of knee pain in advanced radiographic knee OA were calculated using the $95 \%$ confidence intervals (CI). Data were analyzed using SAS (SAS Institute Inc., Cary, NC). All data are presented as the means and standard deviations (SD) if they had a normal distribution and median and interquartile range (IQR) if not, or as percentages. In all analyses, $P<0.05$ (2-tailed) was taken to indicate statistical significance.

\section{Ethics statement}

The HAS study and KNHANES study were approved by the institutional review board of the Hallym University School of Medicine (IRB approval number: HIRB-2007001) and by the Korea Centers for Disease Control and Prevention institutional review board in Korea (201002CON-21-C, 2011-02CON-06-C and 2012-01EXP-01$2 \mathrm{C})$, respectively. Both study protocols conformed to the ethical guidelines of the 1975 Declaration of Helsinki and written informed consent was obtained from each participant.

\section{Results}

The characteristics of the subjects included in the HAS, KNHANES, and OAI are shown in Table 1. The HAS participants were the oldest, followed by those in KNHA NES and OAI with mean ages of 70.1, 64.3, and 61.1 years, respectively. The Korean surveys included more male subjects compared to OAI (54.3 and 56.9\% female in HAS and KNHANES, respectively, compared $58.5 \%$ in OAI). In addition, Korean subjects had lower BMI compared to OAI. The percentages of advanced radiographic knee OA (KL grade 4) were 9.3, 7.6, and $11.5 \%$ in HAS, KNHANES, and OAI, respectively. Among Korean subjects with advanced OA, 23. 5 and $31.2 \%$ in HAS and KNHANES, respectively, did not report pain, while the rate was $5.9 \%$ among OAI subjects.

We compared the clinical characteristics of advanced radiographic knee OA subjects with pain to those without pain. In both Korean groups, the proportion of female subjects was higher in those with pain compared to those without pain $(86.1 \%$ vs. $54.5 \%, P=0.03$ and $87.9 \%$ vs. $77.1 \%, P=0.0003$, in HAS and KNHANES, respectively) (Table 2). In addition, the rate of smokers was lower and the rate of lower education level was higher among subjects with knee pain in the KNHANES group. 
Table 1 Baseline characteristics of the three study groups

\begin{tabular}{|c|c|c|c|c|}
\hline Variables & $\operatorname{HAS}(N=504)$ & KNHANES $(N=10,152)$ & $\mathrm{OAI}(N=4796)$ & $P$-value \\
\hline Age (years), means $\pm S D$ & $70.1 \pm 7.9$ & $64.3 \pm 9.5$ & $61.1 \pm 9.1$ & $<0.0001$ \\
\hline Female & 54.3 & 56.9 & 58.5 & 0.0774 \\
\hline Diabetes & 10.1 & 14.6 & 7.7 & $<0.0001$ \\
\hline CVA & 6.3 & 3.4 & 2.9 & 0.0003 \\
\hline $\mathrm{Ml}$ & 4.5 & 5.1 & 1.9 & $<0.0001$ \\
\hline Hyperlipidemia & 5.7 & 16.3 & NA & $<0.0001$ \\
\hline Osteoporosis & 19.2 & 12.3 & 12.1 & $<0.0001$ \\
\hline BMI $\left(\mathrm{kg} / \mathrm{m}^{2}\right)$, means $\pm \mathrm{SD}$ & $24.6 \pm 3.2$ & $23.9 \pm 3.1$ & $28.6 \pm 4.8$ & $<0.0001$ \\
\hline Smoker & 40.4 & 40.5 & 47.1 & $<0.0001$ \\
\hline Alcohol & 41.4 & 77.5 & 80.3 & $<0.0001$ \\
\hline Low education & 77.9 & 65.2 & 70.9 & $<0.0001$ \\
\hline Low income & 45.9 & 75.2 & 75.7 & $<0.0001$ \\
\hline Marriage & 68.8 & 77.7 & 66.8 & $<0.0001$ \\
\hline $\mathrm{KL}$ grade 4 in any tibio-femoral joint & 9.3 & 7.6 & 11.5 & $<0.0001$ \\
\hline
\end{tabular}

All data are presented as percentages unless otherwise specified. Low education level was defined as < 9 years of education in HAS and KNHANES, and as less than high school graduation in OAI. Low income was defined as the lowest quartile of yearly household income in HAS and KNHANES and as yearly household income lower than $\$ 100,000$ USD in OAI. Continuous variables showing normal distribution (BMI) were tested using ANOVA. Age was tested using Kruskal Wallis test and categorical variables using chi-square test

HAS Hallym Aging Study, KNHANES Korean National Health and Nutrition Examination Survey, OAI Osteoarthritis Initiative, SD Standard deviation, CVA

Cerebrovascular accident, MI Myocardial infarction, KL grade Kellgren-Lawrence grade

While there was no difference in age between asymptomatic and symptomatic subjects in Korean surveys, symptomatic subjects were significantly younger compared to asymptomatic subjects in OAI. In addition, symptomatic subjects had a higher rate of osteoporosis in the Korean groups, while the reverse was true for OAI.
On univariable ordinal regression analysis (Table 3), female gender was significantly associated with the presence of knee pain in both HAS and KHANES groups (odds ratio 5.17[95\% CI, 1.13-23.55] and 3.16[95\% CI, 1.81-5.55], respectively). While non-smokers, the presence of osteoporosis, and lower education level were significantly associated with pain in univariable analysis

Table 2 Comparison of clinical characteristics of advanced radiographic knee OA subjects in three study groups

\begin{tabular}{|c|c|c|c|c|c|c|c|c|c|}
\hline \multirow[b]{2}{*}{ Variables } & \multicolumn{3}{|l|}{ HAS } & \multicolumn{3}{|l|}{ KNHANES } & \multicolumn{3}{|l|}{ OAI } \\
\hline & $\begin{array}{l}\text { Without pain } \\
(N=11)\end{array}$ & $\begin{array}{l}\text { With pain } \\
(N=36)\end{array}$ & $P$ value & $\begin{array}{l}\text { Without pain } \\
(N=214)\end{array}$ & $\begin{array}{l}\text { With pain } \\
(N=471)\end{array}$ & $P$ value & $\begin{array}{l}\text { Without pain } \\
(N=33)\end{array}$ & $\begin{array}{l}\text { With pain } \\
(N=521)\end{array}$ & $P$ value \\
\hline Age (years), means $\pm S D$ & $76.8 \pm 8.9$ & $72.3 \pm 6.8$ & 0.09 & $72.2 \pm 8.0$ & $72.2 \pm 7.8$ & 0.71 & $70.3 \pm 7.6$ & $64.2 \pm 8.7$ & $<.0001$ \\
\hline Female & 54.5 & 86.1 & 0.03 & 77.1 & 87.9 & 0.0003 & 48.5 & 52.4 & 0.66 \\
\hline Diabetes & 9.0 & 11.1 & 0.85 & 15.8 & 19.7 & 0.23 & 12.5 & 9.1 & 0.52 \\
\hline CVA & 0 & 5.5 & 0.42 & 1.8 & 4.2 & 0.12 & 3.1 & 3.3 & 0.95 \\
\hline MI & 0 & 5.5 & 0.42 & 4.6 & 5.3 & 0.73 & 3.2 & 1.9 & 0.63 \\
\hline Hyperlipidemia & 0 & 0 & NA & 11.2 & 16.5 & 0.07 & NA & NA & NA \\
\hline Osteoporosis & 9.0 & 27.7 & 0.2 & 14.2 & 27.6 & 0.0041 & 24.2 & 11.4 & 0.03 \\
\hline $\begin{array}{l}\mathrm{BMI}\left(\mathrm{kg} / \mathrm{m}^{2}\right) \\
\text { means } \pm \mathrm{SD}\end{array}$ & $26.3 \pm 3.8$ & $26.3 \pm 4.6$ & 0.98 & $25.0 \pm 3.8$ & $25.2 \pm 3.8$ & 0.58 & $29.2 \pm 4.1$ & $29.8 \pm 4.5$ & 0.5 \\
\hline Smoker & 18.1 & 25.0 & 0.64 & 25.8 & 16.2 & 0.0033 & 37.5 & 49.7 & 0.18 \\
\hline Alcohol & 45.4 & 38.8 & 0.7 & 63.3 & 60.4 & 0.47 & 78.1 & 82.2 & 0.56 \\
\hline Low education & 100 & 94.4 & 0.42 & 85.9 & 94.9 & $<.0001$ & 96.9 & 95.2 & 0.66 \\
\hline Low income & 66.6 & 59.3 & 0.69 & 78.2 & 81.3 & 0.33 & 80.6 & 78.6 & 0.79 \\
\hline Marriage & 45.4 & 38.8 & 0.7 & 53.7 & 53.7 & 0.1 & 78.1 & 66.8 & 0.19 \\
\hline
\end{tabular}

All data are presented as percentages unless specified otherwise. Continuous variables were tested using two sample t-test and categorical variables using chisquare test. CVA Cerebrovascular accident, MI Myocardial infarction, BMI Body mass index 
Table 3 Risk factors associated knee pain in advanced radiographic knee OA in three study subjects

\begin{tabular}{|c|c|c|c|c|c|c|}
\hline \multirow[t]{2}{*}{ Variables } & \multicolumn{2}{|l|}{$\operatorname{HAS}(N=47)$} & \multicolumn{2}{|c|}{$\operatorname{KNHANES}(N=685)$} & \multicolumn{2}{|l|}{$\mathrm{OAI}(N=554)$} \\
\hline & $\begin{array}{l}\text { Unadjusted OR } \\
(95 \% \mathrm{Cl})\end{array}$ & $\begin{array}{l}\text { Adjusted OR } \\
(95 \% \mathrm{Cl})\end{array}$ & $\begin{array}{l}\text { Unadjusted OR } \\
(95 \% \mathrm{Cl})\end{array}$ & $\begin{array}{l}\text { Adjusted OR } \\
(95 \% \mathrm{Cl})\end{array}$ & $\begin{array}{l}\text { Unadjusted OR } \\
(95 \% \mathrm{Cl})\end{array}$ & $\begin{array}{l}\text { Adjusted OR } \\
(95 \% \mathrm{CI})\end{array}$ \\
\hline Age & $0.91(0.81-1.02)$ & $N A^{c}$ & $0.91(0.81-1.02)$ & - & $0.91(0.86-0.95)$ & $0.91(0.86-0.95)$ \\
\hline Female & $5.17(1.13-23.55)$ & $N A^{c}$ & $3.16(1.81-5.55)$ & $3.16(1.81-5.55)$ & $0.86(0.42-1.73)$ & - \\
\hline Diabetes & $1.25(0.13-12.51)$ & $N A^{c}$ & $1.3(0.85-2)$ & - & $0.7(0.24-2.09)$ & - \\
\hline CVA & $N A^{a}$ & $N A^{c}$ & 2.33(0.79-6.9) & - & $1.06(0.14-8.25)$ & - \\
\hline Ml & $N A^{a}$ & $N A^{c}$ & $1.14(0.54-2.43)$ & - & $0.6(0.07-4.82)$ & - \\
\hline Hyperlipidemia & NA & $N A^{c}$ & $1.57(0.96-2.56)$ & - & NA & - \\
\hline Osteoporosis & $3.85(0.43-34.06)$ & $N A^{c}$ & $2.3(1.29-4.09)$ & - & $0.4(0.17-0.93)$ & - \\
\hline BMI & $1(0.86-1.17)$ & $N A^{c}$ & $1.01(0.97-1.06)$ & - & $1.03(0.95-1.11)$ & - \\
\hline Smoker & $1.5(0.27-8.27)$ & $N A^{c}$ & $0.56(0.38-0.83)$ & - & $1.65(0.79-3.44)$ & - \\
\hline Alcohol & $0.76(0.2-2.98)$ & $N A^{c}$ & $0.88(0.63-1.24)$ & - & $1.29(0.54-3.08)$ & - \\
\hline Low education & $N A^{b}$ & $N A^{c}$ & $3.04(1.73-5.34)$ & - & $1.57(0.21-11.96)$ & - \\
\hline Low income & $0.73(0.15-3.46)$ & $N A^{c}$ & $1.22(0.82-1.82)$ & - & $0.57(0.24-1.33)$ & - \\
\hline Marriage & $0.76(0.2-2.98)$ & & $1(0.72-1.38)$ & - & $0.88(0.35-2.21)$ & - \\
\hline
\end{tabular}

${ }^{a}$ Among subjects without pain, none had this condition. ${ }^{b}$ Among subjects without pain, all had low education level. ${ }^{c}$ In HAS groups, because there were so few subjects, adjustment analysis was not possible. For Adjust in KNHANES and OAl, we used logistic regression analysis with the backward selection method. CVA Cerebrovascular accident, MI Myocardial infarction, BMI Body mass index

among KNHANES subjects, they became insignificant after multivariable adjustment and only female gender remained significant. On the other hand, younger age and osteoporosis were positively and negatively associated with knee pain in OAI subjects, respectively, while only younger age remained significant after multivariable analysis (Table 3). Quality of life assessed with SF-12 was compared between non-OA, advanced OA without pain, and advanced OA with pain subjects in HAS and OAI cohorts (Table 4). Compared to non-OA subjects, advanced OA subjects without pain had comparable scores in all measures except physical function in HAS subjects, while advanced OA subjects with pain had significantly poorer scores compared to non-OA subjects in all measures except for role emotional domain. Quality of life was also comparable between non-OA and advanced OA without pain among OAI subjects. Asymptomatic advanced OA subjects had comparable WOMAC pain, stiffness, and physical function score compared to non-OA subjects in both HAS and OAI,

Table 4 Health related QOL measured by SF-12 in HAS and OAl subjects

\begin{tabular}{|c|c|c|c|c|c|c|}
\hline \multirow[t]{2}{*}{ Variables } & \multicolumn{3}{|l|}{ HAS } & \multicolumn{3}{|l|}{ OAI } \\
\hline & $\begin{array}{l}\text { Non-OA } \\
(n=103)\end{array}$ & $\begin{array}{l}\text { Advanced OA without } \\
\text { pain }(n=11)\end{array}$ & $\begin{array}{l}\text { Advanced OA with } \\
\text { pain }(n=36)\end{array}$ & $\begin{array}{l}\text { Non-OA } \\
(n=588)\end{array}$ & $\begin{array}{l}\text { Advanced OA without } \\
\text { pain }(n=33)\end{array}$ & $\begin{array}{l}\text { Advanced OA with } \\
\text { pain }(n=521)\end{array}$ \\
\hline $\begin{array}{l}\text { Physical } \\
\text { functioning (PF) }\end{array}$ & $66.99 \pm 33.43$ & $47.72 \pm 28.4^{*}$ & $27.85 \pm 32.52^{*}$ & $85.31 \pm 25.26$ & $84.38 \pm 25.20$ & $69.08 \pm 30.91^{*}$ \\
\hline $\begin{array}{l}\text { Role physical } \\
\text { (RP) }\end{array}$ & $75.36 \pm 32.01$ & $70.45 \pm 25.16$ & $35.71 \pm 32.81^{*}$ & $84.41 \pm 21.40$ & $81.25 \pm 23.97$ & $70.47 \pm 25.20^{*}$ \\
\hline Bodily pain (BP) & $82.03 \pm 25.34$ & $75 \pm 27.38$ & $41.42 \pm 30.88^{*}$ & $82.84 \pm 21.27$ & $85.16 \pm 21.87$ & $70.13 \pm 24.37^{*}$ \\
\hline $\begin{array}{l}\text { General health } \\
(\mathrm{GH})\end{array}$ & $48.2 \pm 24.19$ & $44.09 \pm 30.56$ & $25.42 \pm 25.15^{*}$ & $80.96 \pm 19.06$ & $77.66 \pm 17.27$ & $73.39 \pm 19.54^{*}$ \\
\hline Vitality (VT) & $37.62 \pm 29.67$ & $27.27 \pm 23.59$ & $18.57 \pm 22.96^{*}$ & $65.33 \pm 21.09$ & $70.31 \pm 16.11$ & $61.03 \pm 21.69^{*}$ \\
\hline $\begin{array}{l}\text { Social } \\
\text { functioning (SF) }\end{array}$ & $87.86 \pm 24.21$ & $81.81 \pm 35.51$ & $68.57 \pm 33.39^{*}$ & $90.32 \pm 18.69$ & $98.44 \pm 8.84^{*}$ & $89.50 \pm 19.85$ \\
\hline $\begin{array}{l}\text { Role emotional } \\
\text { (RE) }\end{array}$ & $86.04 \pm 21.53$ & $93.18 \pm 16.16$ & $72.5 \pm 35.32$ & $91.04 \pm 15.60$ & $93.75 \pm 14.89$ & $87.86 \pm 19.47^{*}$ \\
\hline PCS & $68.14 \pm 24.16$ & $59.31 \pm 21.43$ & $32.6 \pm 24.25^{*}$ & $80.38 \pm 17.72$ & $82.11 \pm 18.20$ & $70.76 \pm 20.32^{*}$ \\
\hline MCS & $71.6 \pm 18.71$ & $67.61 \pm 20.12$ & $55.98 \pm 23.01^{*}$ & $80.60 \pm 14.59$ & $86.13 \pm 9.72$ & $79.00 \pm 14.97^{*}$ \\
\hline
\end{tabular}

PCS Physical component summary, MCS Mental component summary. Data are presented as the mean \pm SD. ${ }^{*}: P$ value $<0.05$ versus non-OA patients by Mann Whitney test within group 
and total WOMAC score was not significantly different between non-OA and asymptomatic OA subjects in the OAI cohort (Table 5).

\section{Discussion}

In this study, we examined the prevalence of pain among subjects with advanced radiographic knee OA and clinical characteristics associated with pain using two Korean databases and one American database. The results showed that 23.5 and $31.2 \%$ of subjects with KL grade 4 OA were asymptomatic in the Korean group and $5.9 \%$ of subjects with KL grade 4 OA were asymptomatic in the American group. Female gender was significantly associated with pain. Advanced radiographic knee OA subjects without pain did not differ in terms of quality of life compared to non-radiographic OA subjects.

Although many studies have reported that radiographic knee OA is poorly correlated with knee pain, and risk factors for radiographic OA are not strong predictors of knee pain, a study of Caucasian subjects, including patients with knees discordant for the presence of pain or pain severity, showed that the severity of radiographic knee OA was strongly associated with both the presence of frequent knee pain and pain severity [24-26]. That study used a within-person, kneematched, case-control design so that all person-level factors related to pain were distributed evenly between both knees, eliminating their confounding effects between individual subjects. These findings were corroborated by another study in an Asian population, which showed that there was a strong dose-response relationship between the severity of radiographic knee OA and frequent knee pain [27]. Compared to knees with KL grade 0, the odds ratios of frequent knee pain were 3.0-6.8, and 5.954.7 among knees with KL grade 2 and KL grade 3-4, respectively.

These findings indicated that the pathological changes revealed by radiographs were indeed correlated with pain. However, the within-person, knee-matched approach may have inherent limitations due to the possibility of selecting unilateral knee OA with a traumatic etiology. The fact that pain perception is a complex process related to psychosocial factors as well as joint pathology may explain the phenomenon of knee pain in the absence of knee OA. On the other hand, the absence of pain in subjects with severely damaged joints is difficult to explain with the traditional concept of nociceptive sensory input from tissue damage being the main mechanism of pain, and consistent with the concept that pain is a subjective experience unique to each individual, with natural variability among individuals in terms of sensitivity and perception.

Compared to Korean subjects, OAI subjects with advanced OA were mostly symptomatic and only $5.9 \%$ did not have knee pain. This discrepancy may have been related to the differences in study subjects, as well as selection of participants or definition of knee pain. The questionnaires for knee pain differed in the three studies (presence of knee pain lasting at least 1 month during life, or lasting more than 30 days over the past 3 months in the two Korean studies, pain on most days at least 1 month during the past 12 months in OAI), and it is possible that OAI captured pain status more broadly. Our result shows that OAI group had higher prevalence of pain compared to Korean groups. Higher BMI among OAI group compared to Korean group may result in more pain, because previous study showed that OA subjects with high BMI had a greater likelihood of knee pain compared to subjects with a normal BMI [28]. The potential impact of high BMI on pain may be mediated through inflammatory pathways, as well as difference in load bearing [29]. Although ethnic differences in the response to acute pain have been reported [30, 31 , this would not fully account for the results because previous reports in Caucasian populations showed that although there was a direct relationship between the severity of radiographic $\mathrm{OA}$ and knee pain, only $64 \%$ with $\mathrm{KL}$ grade 3 had experienced pain on some occasions [32]. A more recent report showed

Table 5 Health related QOL measured by WOMAC score in HAS and OAI subjects

\begin{tabular}{|c|c|c|c|c|c|c|}
\hline \multirow[t]{2}{*}{ Variables } & \multicolumn{3}{|l|}{ HAS } & \multicolumn{3}{|l|}{ OAI } \\
\hline & $\begin{array}{l}\text { Non-OA }(n= \\
103)\end{array}$ & $\begin{array}{l}\text { Advanced OA without } \\
\text { pain }(n=11)\end{array}$ & $\begin{array}{l}\text { Advanced OA with } \\
\text { pain }(n=36)\end{array}$ & $\begin{array}{l}\text { Non-OA } \\
(n=588)\end{array}$ & $\begin{array}{l}\text { Advanced OA without } \\
\text { pain }(n=33)\end{array}$ & $\begin{array}{l}\text { Advanced OA with } \\
\text { pain }(n=521)\end{array}$ \\
\hline $\begin{array}{l}\text { WOMAC pain } \\
\text { score }\end{array}$ & $53.38 \pm 80.14$ & $98.36 \pm 100.03$ & $285.69 \pm 152.61$ & $2.38 \pm 3.23$ & $1.50 \pm 2.10$ & $5.58 \pm 3.83$ \\
\hline $\begin{array}{l}\text { WOMAC } \\
\text { stiffness score }\end{array}$ & $16.95 \pm 33.53$ & $20.36 \pm 29.76$ & $117.00 \pm 68.67$ & $1.39 \pm 1.64$ & $0.94 \pm 1.22$ & $3.05 \pm 1.74$ \\
\hline $\begin{array}{l}\text { WOMAC } \\
\text { function score }\end{array}$ & $25.52 \pm 34.65$ & $50.00 \pm 41.23$ & $122.31 \pm 59.89$ & $6.91 \pm 10.57$ & $5.37 \pm 7.95$ & $17.77 \pm 12.79$ \\
\hline $\begin{array}{l}\text { Total WOMAC } \\
\text { score }\end{array}$ & $227.11 \pm 321.47$ & $458.27 \pm 424.88^{*}$ & $1364.97 \pm 687.58^{*}$ & $10.55 \pm 14.75$ & $7.71 \pm 10.87$ & $26.13 \pm 17.38^{*}$ \\
\hline
\end{tabular}

HAS group used the $100 \mathrm{~mm}$ visual analog version and WOMAC score range was $0-2400$. OAl group used the Likert scale version and score range was 0-96. Data are presented as the mean $\pm S D$. ${ }^{*}: P$ value $<0.05$ versus non-OA patients by Mann Whitney test within group 
that $25.8 \%$ of Dutch subjects with KL grade 3-4 were also asymptomatic, consistent with our results [12].

Female gender was the only factor associated with pain in Korean advanced OA subjects. This result was consistent with a previous study showing that women reported greater knee pain than men in all KL grades although the gender difference was attenuated at KL grade 4 [33]. In that study, the sex differences in knee OA symptoms were postulated to have been due to differences in hormones, body composition, psychosocial characteristics, knee structure, and neural processing. Another study suggested that enhanced central sensitivity may be an important contributor to the greater overall sensitivity to experimental pain in women compared to men [34].

In the OAI study, younger age was associated with pain. Although a range of painful diseases show higher prevalence in the elderly, older age has been reported to be both positively and negatively associated with knee pain $[8,35]$. Our finding indicated that young individuals may have higher sensitivity to pain. In regression analysis to explore the risk factor associated knee pain in advanced radiographic OA in our study, we didn't adjust for "a history of knee injury" because it was not available for KNHANES cohort. We only included variables that could be identified in all three groups. Because knee injury is a risk factor for knee pain [36], we cannot exclude the possibility that the association between young age and knee pain in the OAI cohort might have resulted from this. However, among Korean subjects, age was not associated with pain in any direction. The reason for the discrepancy in the association of osteoporosis with knee pain in the two ethnic groups remains unclear. Epidemiological studies have frequently shown an inverse association between osteoporosis and OA, with a stronger association for large joint OA. However, there is a paucity of data regarding the relationship between OA pain and osteoporosis [37]. Although osteoporosis is considered to be a major cause of musculoskeletal pain, how osteoporosis causes pain aside from pain resulting from fractures, is poorly understood. Osteoclasts resorb bone by secreting protons into the extracellular compartment, which leads to an acidic microenvironment, a well-known cause of pain [38, 39]. The relationship between osteoporosis and OA pain, and its pathogenetic mechanism is an important subject of further research.

In our study, health-related quality of life was not significantly different between non-OA and asymptomatic advanced radiographic knee OA subjects. Independent of radiographic changes, knee pain has been reported to be an important determinant of physical disability in knee OA [5, 40]. Creamer et al. reported that decreased physical activity due to pain is associated with impaired physical performance in subjects with knee OA.
Therefore, it is plausible that knee pain may lead to a decreased quality of life through impairment of physical performance, independently of the presence of OA [5]. Although therapeutic trials with nerve growth factor suggests that pain control may lead to accelerated degradation of joints, it is also possible that proper control of pain may help to retard the physical disability in OA.

Our study had some limitations. Due to the heterogeneity of data collection methods used, the data could not be combined and analyzed. Some of the discrepancies between cohorts may have been due to the differences in data collection methodologies, such as the questionnaire for knee pain. The definition of asymptomatic knee OA subjects as those who responded "no" to the screening knee pain questionnaire is arbitrary, and may have missed subjects with milder degrees of knee pain. Finally, we did not include patello-femoral OA because KL grade 4 only relates to tibiofemoral OA. How advanced patellofemoral $\mathrm{OA}$ contributes to knee pain would be an important research subject.

\section{Conclusions}

The results of the present study indicated that $5.9-31 \%$ of subjects with radiographic KL grade 4 OA derived from 3 different study populations did not have knee pain Therapeutic decision-making based simply on imaging studies, as well as treatment options focusing solely on cartilage engineering, should be viewed with caution.

\section{Supplementary information}

Supplementary information accompanies this paper at https://doi.org/10 1186/s12891-020-03647-x.

Additional file 1. Questionnaires survey in three groups.

\section{Abbreviations}

AP: Anteroposterior; BMI: Body mass index; BP: Bodily pain; Cl: Confidence intervals; CVA: Cerebrovascular accident; GH: General health; HAS: Hallym aging study; IQR: Interquartile range; KL: Kellgren-Lawrence; KNHA NES: Korean national health and nutrition examination survey; MCS: Mental component summary; MI: Myocardial infarction; OA: Osteoarthritis; OAl: Osteoarthritis initiative; OR: Odds ratio; PA: Posterior-anterior; PCS: Physical component summary; PF: Physical functioning; RE: Role emotional; RP: Role physical; SD: Standard deviations; SF: Social functioning; THR: Total hip replacement; TIA: Transient ischemic attack; TKR: Total knee replacement; VT: Vitality; WOMAC: Western Ontario \& McMaster Universities; YLD: Years lived with disability

\section{Authors' contributions}

KMS and $\mathrm{JH}$ were responsible for the analysis and interpretation of data, drafting the article or revising it critically for important intellectual content, final approval of the version to be submitted. DHK was responsible for the acquisition of data, analysis and interpretation of data. DGJ, MD were responsible for the analysis and interpretation of data. HAK was responsible for the conception and design of the study, analysis and interpretation of data, drafting the article or revising it critically for important intellectual content, final approval of the version to be submitted. All authors read and approved the final manuscript. 


\section{Funding}

This work was supported by a grant of the Korea Health Technology R\&D Project through the Korea Health Industry Development Institute (KHIDI), funded by the Ministry of Health \& Welfare, Republic of Korea (grant number: HI16C0287), a grant of the Basic Science Research Program through the National Research Foundation (NRF) of Korea funded by the Ministry of Education (2017R1A2B2001881), and Hallym University research fund.

\section{Availability of data and materials}

The datasets used and analyzed during the current study are available from the corresponding author on reasonable request.

\section{Ethics approval and consent to participate}

The HAS study and KNHANES study were approved by the institutional review board of the Hallym University School of Medicine (IRB approva number: HIRB-2007-001) and by the Korea Centers for Disease Control and Prevention institutional review board in Korea (2010-02CON-21-C, 2011 02CON-06-C and 2012-01EXP-01-2C), respectively. Both study protocols conformed to the ethical guidelines of the 1975 Declaration of Helsinki and written informed consent was obtained from each participant.

\section{Consent for publication}

\section{Not applicable.}

\section{Competing interests}

The authors declare that they have no competing interests. The OAl is a public-private partnership comprised of five contracts funded by the National Institutes of Health. Private funding partners include Merck Research Laboratories; Novartis Pharmaceuticals Corporation, GlaxoSmithKline; and Pfizer, Inc.

\section{Author details}

${ }^{1}$ Division of Rheumatology, Department of Internal Medicine, Hallym University Dongtan Sacred Heart Hospital, 896, Pyongchon, Hwaseong-si, Anyang, Kyunggi 431-070, South Korea. 'Division of Rheumatology, Department of Internal Medicine, Hallym University Sacred Heart Hospital, Anyang, Kyunggi, South Korea. ${ }^{3}$ Deparment of Social and Preventive Medicine, Hallym University College of Medicine, Chuncheon, Kangwon, South Korea. ${ }^{4}$ Department of Statistics, Seoul National University, Gwanak, Seoul, South Korea. ${ }^{5}$ Department of Radiology, Boston University School of Medicine, Boston, Massachusetts, USA.

\section{Received: 5 March 2020 Accepted: 15 September 2020}

\section{Published online: 29 September 2020}

\section{References}

1. Vos T, Flaxman AD, Naghavi M, Lozano R, Michaud C, Ezzati M, et al. Years lived with disability (YLDs) for 1160 sequelae of 289 diseases and injuries 1990-2010: a systematic analysis for the global burden of disease study 2010. Lancet. 2012;380(9859):2163-96.

2. Hadler NM. Knee pain is the malady--not osteoarthritis. Ann Intern Med. 1992;116(7):598-9.

3. Kim I, Kim HA, Seo Yl, Song YW, Jeong JY, Kim DH. The prevalence of knee osteoarthritis in elderly community residents in Korea. J Korean Med Sci. 2010;25(2):293-8

4. Davis MA, Ettinger WH, Neuhaus JM, Barclay JD, Segal MR. Correlates of knee pain among US adults with and without radiographic knee osteoarthritis. J Rheumatol. 1992;19(12):1943-9.

5. Creamer $P$, Lethbridge-Cejku M, Hochberg MC. Factors associated with functional impairment in symptomatic knee osteoarthritis. Rheumatology (Oxford). 2000;39(5):490-6.

6. Bedson J, Croft PR. The discordance between clinical and radiographic knee osteoarthritis: a systematic search and summary of the literature. BMC Musculoskelet Disord. 2008;9:116

7. McAlindon TE. Editorial: toward a new paradigm of knee osteoarthritis Arthritis Rheumatol. 2015;67(8):1987-9.

8. Jordan JM, Helmick CG, Renner JB, Luta G, Dragomir AD, Woodard J, et al. Prevalence of knee symptoms and radiographic and symptomatic knee osteoarthritis in African Americans and Caucasians: the Johnston County osteoarthritis project. J Rheumatol. 2007;34(1):172-80.

9. Muraki S, Oka H, Akune T, Mabuchi A, En-yo Y, Yoshida M, et al. Prevalence of radiographic knee osteoarthritis and its association with knee pain in the elderly of Japanese population-based cohorts: the ROAD study. Osteoarthr Cartil. 2009;17(9):1137-43.

10. Turkiewicz A, Gerhardsson de Verdier M, Engstrom G, Nilsson PM, Mellstrom $C$, Lohmander LS, et al. Prevalence of knee pain and knee OA in southern Sweden and the proportion that seeks medical care. Rheumatology (Oxford). 2015;54(5):827-35.

11. Zhang Y, Xu L, Nevitt MC, Aliabadi P, Yu W, Qin M, et al. Comparison of the prevalence of knee osteoarthritis between the elderly Chinese population in Beijing and whites in the United States: the Beijing osteoarthritis study. Arthritis Rheum. 2001;44(9):2065-71.

12. Schiphof D, Kerkhof HJ, Damen J, de Klerk BM, Hofman A, Koes BW, et al. Factors for pain in patients with different grades of knee osteoarthritis. Arthritis Care Res (Hoboken). 2013;65(5):695-702

13. Duncan R, Peat G, Thomas E, Hay E, McCall I, Croft P. Symptoms and radiographic osteoarthritis: not as discordant as they are made out to be? Ann Rheum Dis. 2007;66(1):86-91

14. Keurentjes JC, Fiocco M, So-Osman C, Onstenk R, Koopman-Van Gemert $A W$, Poll RG, et al. Patients with severe radiographic osteoarthritis have a better prognosis in physical functioning after hip and knee replacement: a cohort-study. PLoS One. 2013;8(4):e59500.

15. Romero Jurado M, Enrique Fidalgo A, Rodriguez Villar V, Mar Medina J, Soler LB. Factors related with the time to surgery in waiting-list patients for knee prostheses. Reumatol Clin. 2013;9(3):148-55.

16. Byun AR, Lee SW, Lee HS, Shim KW. What is the most appropriate lipid profile ratio predictor for insulin resistance in each sex? A cross-sectional study in Korean populations (the fifth Korea National Health and nutrition examination survey). Diabetol Metab Syndr. 2015;7:59.

17. Park Y, Shin JA, Yang SW, Yim HW, Kim HS, Park YH. The relationship between visual impairment and health-related quality of life in Korean adults: the Korea National Health and nutrition examination survey (20082012). PLoS One. 2015;10(7):e0132779.

18. Shin D. Association between metabolic syndrome, radiographic knee osteoarthritis, and intensity of knee pain: results of a national survey. J Clin Endocrinol Metab. 2014;99(9):3177-83.

19. Pollard B, Johnston M, Dixon D. Exploring differential item functioning in the Western Ontario and McMaster universities osteoarthritis index (WOMAC). BMC Musculoskelet Disord. 2012;13:265.

20. Villanueva I, del Mar GM, Javier Toyos F, Ariza-Ariza R, Navarro F. Relative efficiency and validity properties of a visual analogue vs a categorical scaled version of the Western Ontario and McMaster universities osteoarthritis (WOMAC) index: Spanish versions. Osteoarthr Cartil. 2004;12(3):225-31.

21. Kersten P, White PJ, Tennant A. The visual analogue WOMAC 3.0 scale-internal validity and responsiveness of the VAS version. BMC Musculoskelet Disord. 2010;11:80.

22. Webster KE, Feller JA. Comparison of the short form-12 (SF-12) health status questionnaire with the SF-36 in patients with knee osteoarthritis who have replacement surgery. Knee Surg Sports Traumatol Arthrosc. 2016;24(8):2620-6.

23. Lee S, Kim TN, Kim SH. Sarcopenic obesity is more closely associated with knee osteoarthritis than is nonsarcopenic obesity: a cross-sectional study. Arthritis Rheum. 2012;64(12):3947-54

24. Felson DT, Lawrence RC, Dieppe PA, Hirsch R, Helmick CG, Jordan JM, et al. Osteoarthritis: new insights. Part 1: the disease and its risk factors. Ann Intern Med. 2000;133(8):635-46.

25. Felson DT, Zhang Y. An update on the epidemiology of knee and hip osteoarthritis with a view to prevention. Arthritis Rheum. 1998:41(8):1343-55.

26. Neogi T, Felson D, Niu J, Nevitt M, Lewis CE, Aliabadi P, et al. Association between radiographic features of knee osteoarthritis and pain: results from two cohort studies. BMJ. 2009;339:b2844.

27. Wang K, Kim HA, Felson DT, Xu L, Kim DH, Nevitt MC, et al. Radiographic knee osteoarthritis and knee pain: cross-sectional study from five different racial/ethnic populations. Sci Rep. 2018;8(1):1364.

28. Rogers MW, Wilder FV. The association of BMl and knee pain among persons with radiographic knee osteoarthritis: a cross-sectional study. BMC Musculoskelet Disord. 2008:9:163.

29. Berenbaum F, Eymard F, Houard X. Osteoarthritis, inflammation and obesity. Curr Opin Rheumatol. 2013;25(1):114-8.

30. Bates MS, Edwards WT, Anderson KO. Ethnocultural influences on variation in chronic pain perception. Pain. 1993;52(1):101-12.

31. Walsh NE, Schoenfeld L, Ramamurthy S, Hoffman J. Normative model for cold pressor test. Am J Phys Med Rehabil. 1989;68(1):6-11. 
32. Lethbridge-Cejku M, Scott WW Jr, Reichle R, Ettinger WH, Zonderman A, Costa $\mathrm{P}$, et al. Association of radiographic features of osteoarthritis of the knee with knee pain: data from the Baltimore longitudinal study of aging. Arthritis Care Res. 1995:8(3):182-8.

33. Glass N, Segal NA, Sluka KA, Torner JC, Nevitt MC, Felson DT, et al. Examining sex differences in knee pain: the multicenter osteoarthritis study. Osteoarthr Cartil. 2014;22(8):1100-6.

34. Bartley EJ, King CD, Sibille KT, Cruz-Almeida Y, Riley JL 3rd, Glover TL, et al. Enhanced Pain Sensitivity Among Individuals With Symptomatic Knee Osteoarthritis: Potential Sex Differences in Central Sensitization. Arthritis Care Res (Hoboken). 2016;68(4):472-80.

35. Dillon CF, Rasch EK, Gu Q, Hirsch R. Prevalence of knee osteoarthritis in the United States: arthritis data from the third National Health and nutrition examination survey 1991-94. J Rheumatol. 2006;33(11):2271-9.

36. Muraki S, Akune T, Oka H, Ishimoto Y, Nagata K, Yoshida M, et al. Incidence and risk factors for radiographic knee osteoarthritis and knee pain in Japanese men and women: a longitudinal population-based cohort study. Arthritis Rheum. 2012;64(5):1447-56.

37. Sambrook P, Naganathan V. What is the relationship between osteoarthritis and osteoporosis? Baillieres Clin Rheumatol. 1997;11(4):695-710

38. Nagae M, Hiraga T, Wakabayashi H, Wang L, Iwata K, Yoneda T. Osteoclasts play a part in pain due to the inflammation adjacent to bone. Bone. 2006; 39(5):1107-15

39. Rousselle AV, Heymann D. Osteoclastic acidification pathways during bone resorption. Bone. 2002;30(4):533-40.

40. Kaukinen P, Podlipska J, Guermazi A, Niinimaki J, Lehenkari P, Roemer FW, et al. Magnetic resonance imaging (MRl)-defined cartilage degeneration and joint pain are associated with poor physical function in knee osteoarthritis the Oulu knee osteoarthritis study. Osteoarthr Cartil. 2017;25(11):1829-40.

\section{Publisher's Note}

Springer Nature remains neutral with regard to jurisdictional claims in published maps and institutional affiliations.

Ready to submit your research? Choose BMC and benefit from:

- fast, convenient online submission

- thorough peer review by experienced researchers in your field

- rapid publication on acceptance

- support for research data, including large and complex data types

- gold Open Access which fosters wider collaboration and increased citations

- maximum visibility for your research: over $100 \mathrm{M}$ website views per year

At $\mathrm{BMC}$, research is always in progress.

Learn more biomedcentral.com/submissions 